\section{International Journal of Medical Research and Review}

\title{
Comparative study of renal function test and thyroid hormone in chronic kidney disease
}

\section{Singhal N. ${ }^{\mathbf{1}}$, Mathur R. ${ }^{2}$, Kumar Bhargava A. ${ }^{3 *}$, Gupta D. ${ }^{4}$ \\ DOI: https://doi.org/10.17511/ijmrr.2020.i06.10}

\footnotetext{
1 Nitesh Singhal, Ph.D. Scholar, Department of Biochemistry, Medical College, Kota, Rajasthan, India.

2 R.D. Mathur, Associate Professor, Department of Medicine, SRG Hospital and Jhalawar Medical College, Jhalawar, Rajasthan, India.

3* Ajay Kumar Bhargava, Senior Professor, Department of Biochemistry, SRG Hospital and Jhalawar Medical College, Jhalawar, Rajasthan, India.

${ }^{4}$ Deepak Gupta, Senior Professor, Department of Medicine, SRG Hospital and Jhalawar Medical College, Jhalawar, Rajasthan, India.
}

Introduction: Biochemical parameters (urea, creatinine, uric acid, T3, T4, TSH) important in prognosis, monitoring of thyroid dysfunction, and chronic kidney disease. The present study was attempted to analyze these parameters in CKD patients and a healthy control group. Materials and methods: Fifty healthy control and 50 were chronic kidney disease subjects were taken serum urea, creatinine uric acid analyzed on the auto analyzer and T3, T4, TSH estimated on immunoassay analyzer. Ethical permission was taken from the institutional ethical committee. Results: Level of urea, creatinine, uric acid, and thyroid hormone T3, T4, TSH were found to be significant in the present study when compared with the control group. $(\mathrm{P}<0.0001)$. Conclusion: It was observed that levels of urea, creatinine, uric acid, and T3, T4, TSH deranged value found in chronic kidney disease subjects.

Keywords: Chronic kidney disease (CKD), Thyroid hormone (T3, T4, TSH)

Corresponding Author

Ajay Kumar Bhargava, Senior Professor, Department of Biochemistry, SRG Hospital and Jhalawar Medical College, Jhalawar, Rajasthan, India. Email: bhargavaajay40@yahoo.com

\section{How to Cite this Article}

Singhal N, Mathur RD, Bhargava AK, Gupta D. Comparative study of renal function test and thyroid hormone in chronic kidney disease. Int J Med Res Rev. 2020;8(6):429-433.

Available From

https://ijmrr.medresearch.in/index.php/ijmrr/article/ view/1234
To Browse

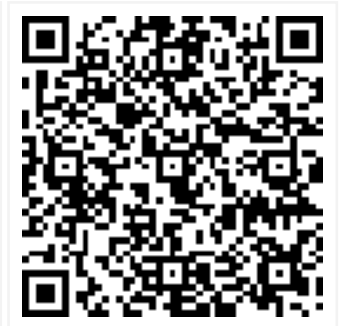

Manuscript Received 2020-12-15

Conflict of Interest No

Review Round 1
2020-12-21
Funding
Nil

Review Round 2 2020-12-25

Ethical Approval Yes
Review Round 3

Accepted 2020-12-27

Plagiarism $\mathbf{X}$-checker $7 \%$

Note

(C) 2020 by Nitesh Singhal, R.D. Mathur, Ajay Kumar Bhargava, Deepak Gupta and Published by Siddharth Health Research and Social Welfare Society. This is an Open Access article licensed under a Creative Commons Attribution 4.0 International License https://creativecommons.org/licenses/by/4.0/ unported [CC BY 4.0]. 


\section{Introduction}

Chronic kidney disease (CKD) is a global health burden [1] due to loss of renal function progressively [2] and is a pathophysiological process with multiple etiologies which is like diabetes, hypertension and $25-40 \%$ of chronic kidney disease may develop chronic renal failure (CRF) and end-stage renal disease (ESRD).Chronic kidney disease prevalence in the Indian population approximately $18 \%$ [3].

The main cause of chronic kidney disease due to deterioration of kidney function and further loss of nephron other causes of CKD are metabolic disease, renal vascular disorders, immunologic disorders,[4] infection, primary tubular disorders, urinary tract obstruction, and congenital disorders.

When there is kidney damage and the kidney are not able to filter waste efficiently, creatinine concentration in serum is maintained by the balance between its generation and excretion by the kidney [5]. Urea is an organic compound and plays a vital role in the nitrogen-containing compound. It is a waste product from dietary protein and is also filtered into urine by the kidney [6][7].

Urea and creatinine are important parameters in diagnosis, the prognosis of follow up of chronic kidney disease [8]. Uric acid is the end product of purine metabolism is excreted by the kidney and its level is important in the reduced glomerular filtrate rate [9].

Kidney plays an important role in the metabolism of thyroid hormone, chronic kidney disease cause uremia and affects the hypothalamus-pituitary thyroid axis which impairs synthesis and secretion of triiodothyronine (T3) and tetraiodothyronine (T4) [10]. Determination of urea, creatinine, and uric acid, and thyroid hormone (T3, T4, TSH) is important in diagnosis, prognosis, and medical management of chronic kidney disease population in the present study.

\section{Materials and Methods}

The present study was conducted in the Department of Biochemistry and medicine in SRG Hospital and Jhalawar Medical College Jhalawar (Rajasthan) in 100 Subjects among then 50 were chronic kidney disease cases from the dialysis ward of the medicine department and 50 healthy control without any disease.

\section{Inclusion Criteria}

- Subjects with chronic kidney disease with no other associated disease such as diabetes mellitus, cancer, tuberculosis

- Male and female group of different age group

- A parameter with suggestive criteria of chronic kidney disease

\section{Exclusion Criteria}

- Any systemic disease such as Liver disease, psychiatric disease, and connective disease

- Subjects with diabetes mellitus

- Subjects on medication such as anticancer, antithyroid drug and steroid drug

- Pregnancy

Serum sample separated from the blood of study subjects both case and control for determination serum urea, creatinine, uric acid. These parameters were estimated on a fully automated analyzer (Backman Au 680) using a commercial Kit.

Thyroid hormone TSH, T3, T4 was estimated on immunoassay analyzer by chemiluminescence method (Maglumi 1000)

The setting of study- Department of biochemistry in tertiary care hospital of Haroti region of Rajasthan, North India.

Duration and type of study- Present study conducted from December 2017 to August 2018.

Ethical consideration and permission- Written consent was taken from all participants and ethical permission was taken from the college ethical committee

Sample size calculation- Total number of 100 subjects recorded among them 50 were admitted to the dialysis unit of the Medicine department and 50 were healthy control subjects.

Data collection procedure- Selection of subjects for the study was made based on a detailed history and proper clinical examination such as name, sex, age, address. For the diagnosis of chronic kidney disease, clinical history, and physical findings with supportive biochemical evidence were taken as criteria.

Statistical analysis- Microsoft Excel worksheets were used and data were analyzed using SPSS version 20.00 . 


Table-1: Normal Level of Biochemical
parameter.
\begin{tabular}{|l|l|}
\hline \multicolumn{1}{|c|}{ Biochemical Parameter } & \multicolumn{1}{c|}{ Range } \\
\hline Urea & $14-45 \mathrm{mg} / \mathrm{dl}$ \\
\hline Creatinine & $0.6-1.5 \mathrm{mg} / \mathrm{dl}$ \\
\hline Uric acid & $3-7 \mathrm{mg} / \mathrm{dl}$ (Male) \\
\hline $3-5 \mathrm{mg} / \mathrm{dl}$ (Female) & \\
\hline $\mathrm{TSH}$ & $0.4-4.5 \mathrm{micro} \mathrm{IU} / \mathrm{mL}$ \\
\hline $\mathrm{T} 3$ & $0.69-2.15 \mathrm{ng} / \mathrm{mL}$ \\
\hline $\mathrm{T} 4$ & $52-127 \mathrm{ng} / \mathrm{mL}$ \\
\hline
\end{tabular}

All the above parameters were performed by the commercial kit method.

Data were demonstrated as mean \pm S.D. and healthy control group compared with CKD patients' group for determination of statically $P$ value for significant or insignificant value.

\section{Results}

In the present study, 50 healthy control subjects (group I) were enrolled, the mean age was 34.56 among them, 31 female and 19 male. In chronic kidney disease (group II) the mean age was 38.00 among them 20 female and 30 were male subject. (Table-2). In the present study, Control and case renal function teat parameter were compared (Urea, Creatinine, and Uric acid) and found to be significant in all parameter $(p<0.0001)$ and thyroid function test parameters (T3, T4, TSH) ( $p$ $<0.0001)$. The statistical analyzed data were compared to the control group I with case group II and was demonstrated as mean \pm S.D. and $\mathrm{P}$ Valve to be expressed as significant $(p<0.05)$ (Table-3).

Table-2: Distribution of age and gender.

\begin{tabular}{|l|l|l|l|}
\hline \multicolumn{1}{|c|}{ Group } & Male & \multicolumn{1}{c|}{ Female } & \multicolumn{1}{c|}{ Mean age ( + S.D.) } \\
\hline I (Control) & 19 & 31 & $34.56+14.68$ \\
\hline II (Case) & 30 & 20 & $38.00+13.39$ \\
\hline
\end{tabular}

Table-3: Mean Level of renal function test and thyroid function test (Mean+S.D.).

\begin{tabular}{|l|l|l|l|l|l|l|}
\hline \multicolumn{1}{|c|}{ Group } & \multicolumn{1}{|c|}{ Urea } & \multicolumn{1}{c|}{ Creatinine } & \multicolumn{1}{c|}{ Uric acid } & \multicolumn{1}{c|}{ T3 } & \multicolumn{1}{c|}{ T4 } & \multicolumn{1}{c|}{ TSH } \\
\hline $\mathrm{I} *$ (Control) & $18.71+5.9$ & $0.58+0.19$ & $3.906+1.162$ & $1.37+0.32$ & $91.67+13.84$ & $1.77+0.95$ \\
\hline $\mathrm{II} *($ Case $) *$ & $126.28+54.30$ & $0.74+37$ & $5.90+1.83$ & $0.83+0.40$ & $74.38+18.73$ & $2.80+1.71$ \\
\hline
\end{tabular}

\section{* Significant $(p<0.0001)$}

\section{Discussion}

Chronic kidney disease is defined as a glomerular filtration rate (GFR), $60 \mathrm{ml} / \mathrm{min} / 173 \mathrm{~m}$ for three months or more. Biochemical parameters in CKD patients and control groups such as urea, creatinine, uric acid, T3, T4, TSH were determined. In the present study table, -1 shows the reference range of urea, creatinine, uric acid, T3, T4, and $\mathrm{TSH}$. These reference ranges are of biochemistry laboratory SRG Hospital and Jhalawar Medical College, Jhalawar (Raj). The mean age of the control group and case group (male and female) were found to be no significant differences when compared to both groups (Table-2). Other workers reported the mean age of CKD subjects male and female group and which are similar to our results. Urea estimation is done by the qualitative enzymatic method in the present study and it was found highly significant $(p<0.0001)$ when compared both control and case group, similar results was observed earlier reported study [10] and increased level of urea and creatinine excretion in blood by impaired kidney function.
Urea is the end product of purine metabolism that accumulate in the blood of a patient with renal failure and cause uremia. Increased level of urea and decreased value of T3 and T4 and increased TSH level observed in CKD subjects Creatinine was produced by non-enzymatic dehydration of creatinine and produced at a constant rate and excreted from the body through kidney glomerular filtration.

Decreased renal function, results in an increased level of creatinine in the present study because of the inability to clear creatinine through urine excretion, other workers' results also agree to our findings [11]. Decreased T3 and T4 and increased TSH observed in CKD patients with increased creatinine in the present study.

Uric acid determined in the serum of control and case subjects which were found to be increased and statistically significant when compared both groups, our results are similar to demonstrated in the literature and which described that GFR falls than increased in the fractional urinary execration but these processes do not fully compensate and serum uric acid level rise $[12,13]$. 
T3, T4 decreased and TSH increased with the increased value of urea, creatinine, and uric acid in chronic kidney disease subjects when compared to the control group.

Decreased level of T3, T4 in chronic kidney disease patient causes hypothyroidism [14] which demonstrated by research worker and described reduced glomerular filtration rate $[15,16]$, altered TSH circadian rhythm and TSH glycosylation [17]. Chronic kidney disease subject's thyroid function alternation due to many factors such as reduced level of thyroid hormone, altered binding to a carrier protein, and derange value of iodine in thyroid tissue [18].

Inflammatory markers such as interleukin 6 (IL 6), $\mathrm{C}$ - reactive protein (CRP) contribute to inflammation in CKD patients and showed a decreased level responsible for inflammation [19]. In the present study determination of urea, creatinine, uric acid, T3, T4, and TSH was important parameters for prognostic and management of chronic kidney disease patients.

\section{Limitation}

In the present study short duration and the small sample size is the limitation of the study.

\section{Conclusion}

Evaluation of Biochemical parameters (urea, creatinine, uric acid, T3, T4, TSH) in chronic kidney disease in the present study found to be significant markers and their deranged value important in progression, monitoring, and management of thyroid function as well as in chronic kidney disease.

\section{What does the study add to the existing knowledge}

Chronic kidney disease patient's biochemical parameter thyroid hormone level important in the management of CKD and thyroid disorder.

\section{Authors contribution}

Dr. Nitesh Singhal- Has conceptualized the study, literature survey, Laboratory work

Dr. R.D. Mathur-Contributed patient selection, sample collection, and entry.

Dr. Ajay Kumar Bhargava- All the data reviewed, paper writing.
Dr. Deepak Gupta- Taken history of patients, draft manuscript, and guided in completion of the manuscript.

\section{Reference}

01. Langovan Veerappan and Georji Abraham. chapter 130 chronic kidney disease- Current status. challenges and management in India. $2012 ; 593$.

[Crossref]

02. Singhal N, Bhargava AK, Pandey S. Study of thyroid hormone (T3,T4,TSH) level in dialyzed chronic kidney disease (CKD) patients. J Med Sci Clin Rese. 2019;7(14)304-309. doi: $10.18535 / j m s c r / v 7 i 4.53$ [Crossref]

03. Brenner and Recturo's. The Kidney, Rober A, Tenton, Jepee practorians. Anatomy of kidney. 11 th ed;2016.

[Crossref]

04. Fauci B, Kasper, Braunwald Hauser. Longo. Harrison's Principle of internal medicine. 17th ed;2008.

[Crossref]

05. Caroll LE. The Stage of chronic kidney disease and the estimate glomerular filtration rate. The Journal of Lancaster General Hospital. 2016;1(2)64-69.

[Crossref]

06. Nisha R, Shrinivasakannan S R, Thango Merriappan K, Jagatha P. Biochemical evaluation of creatinine and urea in patients with renal failure undergoing hemodialysis. Journal of Clinical Pathology and Laboratory Medicine. 2017;1(2)151-155.

[Crossref]

07. Rober K Murray, Daryl K, Granner petter A Mayar, Victor W Rodheel. In Harpers Biochemistry. 25th ed;Lange Medical Publication. 2000.

[Crossref]

08. Laurence M, Tierney, jr stephen S MacPhee and maxim A, Popadakis. Current Medical Diagnosis \& Treatment. 43rd ed;2004.

[Crossref]

09. Rajagopalan B, Dolia PB, Arumalla VK, Seshadri Reddy $V$. Renal function markers and thyroid hormone status in undialyzed chronic kidney disease. Al Ameen J Med Sci. 2013;6(1)70-74. [Crossref] 
10. Iglesias $P$, Díez Jj. Thyroid dysfunction and kidney disease. Europe J Endocrinol. $2009 ; 16(2) 204-213$.

doi: $10.1530 /$ EJE-08-0837 [Crossref]

11. Wu, Alan HB. Tietz Clinical Guide to Laboratory Tests. 4th edition; WB Saunders. 2006.

[Crossref]

12. Mohandas R, Johnson R. Uric acid level increase risk for New-onset kidney disease. Am Soc Nephrol. 2008;19(12)2251-2253.

doi: 10.1681/ASN.2008091012 [Crossref]

13. Srivastava S, Rajput J, Shrivastava M, Chandra R, Gupta M, Sharma R. Correlation of thyroid hormone profile with biochemical markers of renal function in patients undialysed chronic kidney disease. Indian J Endocrinol Metabol. 2018;22(33)316-320.

doi: 10.4103/ijem.IJEM_475_17 [Crossref]

14. Basu G. Interaction between thyroid disorders and kidney disease. Indian Journal of Endocrinology and Metabolism. 2012;16(2)204203.

doi $10.4103 / 2230-8210.93737$ [Crossref]
15. John E. Hall. Arthur C, Guyton. Textbook of Medical Physiology.

Chapter 3. kidney disease and Diuretics. 11th ed. 2006;402-415 [Crossref]

16. Mariani LH, Berns JS. The renal manifestations of thyroid disease. J Am Soc Nephrol. 2012;23(1)22-26.

doi: 10.1681/ASN2010070766 [Crossref]

17. Entedhar RS, Nawal AM. Biochemical changes in chronic renal failure pre- and post-hemodialysis. J Environ Sci Eng Technol. 2016;5;190-195. [Crossref]

18. Zoccali C, Tripepi G, Cutrupi S, Pizzini P, Mallamai $F$. Low triiodothyronine a new facet of inflammation in end stage renal disease. J AM Soc Nephrol. 2005;16(9)2789-2795.

doi: 10.10, 1681/ASN/2005 [Crossref]

19. Zhou J, LI HB, XR Zhy XR, Song HL, Zhao YY, Yang JK. Subclinical hypothyroidism and the risk of chronic kidney disease in T2D subjects- A case control and dose response analysis Medicine (Baltimore). 2017;96(15)e6519. doi: 10.

1097/MD.0000000000006519 [Crossref] 